\title{
Intraparenchymal Epithelial (Enterogenous) Cyst of the Medulla Oblongata
}

\author{
Boleslaw Lach, Neville Russell, David Atack and Brien Benoit
}

\begin{abstract}
MRI examination in a 66year-old woman with a nine year history of progressive brainstem dysfunction and three negative CT scan examinations. Craniotomy and drainage of the cyst to the IVth ventricle led to remarkable clinical recovery. Biopsy of the wall of the cyst revealed an epithelial lining with tonofilaments, desmosomes and surface coating on ultrastructural examination. Immunohistochemistry demonstrated positive reactions of epithelium for keratins, cytokeratins, epithelial membrane antigen and Ulex Europeus lectin, indicating endodermal origin of the cyst.
\end{abstract}

RÉSUMÉ: Kyste épithélial intraparenchymateux (entérogène) du bulbe rachidien Un diagnostic de kyste intraparenchymateux solitaire du bulbe rachidien a été posé sur un examen par NMR chez une femme âgée de 66 ans avec une histoire de dysfonction progressive du tronc cérébral évoluant depuis neuf ans. Trois tomodensitométries avaient été négatives. On a procédé par crâniotomie au drainage du kyste dans le IVe ventricule, entraînant une récupération clinique remarquable. À l'examen ultrastructural d'une biopsie de la paroi du kyste, on a observé un revêtement épithélial avec des tonofilaments, des desmosomes et un enduit en surface. Des études immuno-histochimiques ont montré des réactions positives de l'épithélium pour la kératine, la cytokératine, l'antigène de la membrane épithéliale et la lectine Ulex Europeus, indiquant l'origine endodermale du kyste.

Can. J. Neurol. Sci. 1989; 16:206-210

Epithelial cysts of the neuraxis are rare benign lesions that can occur at any age and at many sites within the central nervous system (CNS). ${ }^{1-5}$ They represent a heterogenous group of malformations lined by epithelia with morphological and histochemical characteristics that suggest derivation from disparate extracranial and intracranial sources. Classification of these cysts is based upon the presumed origin of their epithelium. They have been described under a variety of names reflecting their hypothetical or demonstrated nature: ependymal,2.6-8 glioependymal, ${ }^{9}$ neuroepithelial, ${ }^{10-12}$ enterogenous or neuroenteric, ${ }^{13-16}$ bronchogenic, ${ }^{17}$ respiratory epithelial cyst, 18 foregut cyst, ${ }^{19}$ and choroid plexus ${ }^{20-23}$ and paraphyseal cysts ${ }^{23}$ or simply epithelial,4,24.26 or epithelium-lined 27 cysts. These lesions may be located in the CNS parenchyma, in the meninges along the neuroaxis or within the ventricular system. Intraparenchymal cysts of the CNS involving the brainstem or cerebellum are exceedingly rare.7,9,11,13,15,27-30 Limited immunohistochemical and ultrastructural studies of several intracerebral cysts have been previously reported $12,15,28,31$ with results that reflect their histogenetic diversity. We describe an intraparenchymal epithelial cyst of the medulla oblongata diagnosed with the aid of magnetic resonance imaging (MRI) and treated surgically.

\section{Clinical History}

A 66-year-old right-handed woman was first seen in July 1982 because of a two-year history of progressive symptoms of impaired temperature appreciation, feelings of coldness involving the right side of the face, neck and arm, a slight parasthesia of the tips of the digits of both hands and minimal weakness of the right upper extremity. Neurological examination revealed bilateral weakness of eye abduction, diminished pinprick sensation and temperature perception over the right side of the face, neck, right arm and right upper trunk, as well as mild weakness of arm and hip flexors on the right side.

In July 1987, approximately seven years from the onset of symptoms, she was seen again because of ataxia and intermittent vertigo, horizontal diplopia more noticeable on gaze to the left, occasional sharp stabbing left hemicranial pain and mild intermittent dysphagia. In addition to the previous findings, examination revealed slight impairment of upward gaze, a few beats of vertical nystagmus with upgaze and prominent sustained vertical nystagmus on downgaze. Corneal reflexes were reduced bilaterally. Rapid alternating movements were slightly slower on the right but finger-nose tests were normal. Her gait was mildly

From the Division of Anatomical Pathology (Neuropathology) (BL), Division of Neurosurgery (NR; BB) and Division of Neurology (DA), Ottawa Civic Hospital and University of Ottawa

Received October 8, 1988. Accepted in final form February 9, 1989

Reprint requests to: Dr. B. Lach, Laboratory Medicine, Ottawa Civic Hospital, 1053 Carling Ave., Ottawa, Ontario, Canada KIY 4E9 
wide-based and tandem walking was severely impaired with a tendency to veer equally to the left and right. Extensive blood and CSF investigations were normal. Visual, auditory brain stem and somato-sensory evoked potential studies were within normal limits. Three CT-scan examinations during the course of her disease revealed no abnormalities. An MRI scan performed during her last hospital admission showed a large space-occupying cystic lesion replacing most of the medulla oblongata (Figure la and $1 \mathrm{~b}$ ). The lesion did not communicate with the $1 V$ th ventricule or the compressed cisterna magnum.

Surgery: A posterior fossa exploration revealed a thin-walled cyst on the left side of the medulla oblongata at the proximal end of the IVth ventricle. It was separated from the ventricular lumen by a thin transparent membrane. Fine needle aspiration of the cyst revealed clear colourless CSF-like fluid. After incision, the cyst showed smooth glistening walls. The membranous portion of the cyst wall was excised and free communication between the cyst and the IVth ventricle established.

The patient recovered rapidly from surgery and was discharged home two weeks later. At three month follow-up, down-beating nystagmus was still present but no other abnormalities were noted on examination. Repeat MRI scan showed a collapsed cyst communicating with the IVth ventricle.

\section{METHODS}

Small fragments of the wall of the cyst were processed for light microscopy and stained with hematoxylin and eosin, Wilder reticulin and periodic acid-Schiff reaction. Polyclonal antisera $(P)$ or monoclonal antibodies $(M)$ were used for the tissue localization of the following antigens (sources and dilutions of primary antisera given in the brackets): Glial fibrillary acidic protein (GFAP, Dako I:200,P and AMAC Inc. Westbrooke $1: 75, M$ ), vimentin (VIM, Eurodiagnostics 1:75,P and Labsystems, Helsinki 1:200,M), keratin (KER 56 and 64 kD molecular weight, Dako $1: 200, P$ ), cytokeratin (CK 44,45,52 and $54 \mathrm{kD}$ molecular weight, Labsystems, Helsinki l:400,M), $70 \mathrm{kD}$ neurofilament protein (NF, Sanbio, 1:10,M), Ricinus communis lectin (RC Vector Laboratories 1:2000,P), Ulex Europeus lectin (UE Vector Labs 1:1000,P), S-100 protein (Chemicon 1:100,M), Neuron-specific enolase (NSE, Dako 1:50,P), Leu Ml (Becton-Dickinson, Ca, 1:400,M), Prealbumin (Pre-Alb, Dako 1:200), Leu 7 (Becton-Dickinson, Ca, 1:200,M). Standard peroxidase anti-peroxidase (PAP) method was used for polyclonal antibodies while Avidin-Biotin method was applied for the majority of monoclonal antibodies as previously described. ${ }^{32}$ Monoclonal antibodies were incubated according to recommendations of the producers. (Vector Laboratories, Burlington, Ca, USA). Sections of brain, peripheral nerve, lymph node, squamous carcinoma, adenocarcinoma and astrocytoma were used as positive controls. For the negative controls, the first layer of primary antisera was omitted.

For electronmicroscopy small tissue samples were prepared as previously described ${ }^{34}$ and examined in Philips 200 microscope.

\section{Results}

Light microscopy examination of the wall of the cyst revealed an attenuated single layer of epithelial cells resting on a thin basal lamina and a narrow band of collagenous connective tissue (Figure $2 a$ ). The adjacent brain tissue showed scattered hypertrophic astrocytes and very few normal neurons. PAP revealed positive reactions for CK, KER and UE on the side of the lining of the cyst (Table 1), (Figure 2b). The opposite side of the cyst, corresponding to the floor of the IVth ventricle, showed cuboidal ependymal cells of the IVth ventricle, immunoreactive for S-100, NSE and GFAP. Both, ependyma and lining of the cyst were positive for RC lectin and EMA with monoclonal antibodies. Neither side of the specimen showed activity for Leu 7, M1, Pre-Alb or VIM.

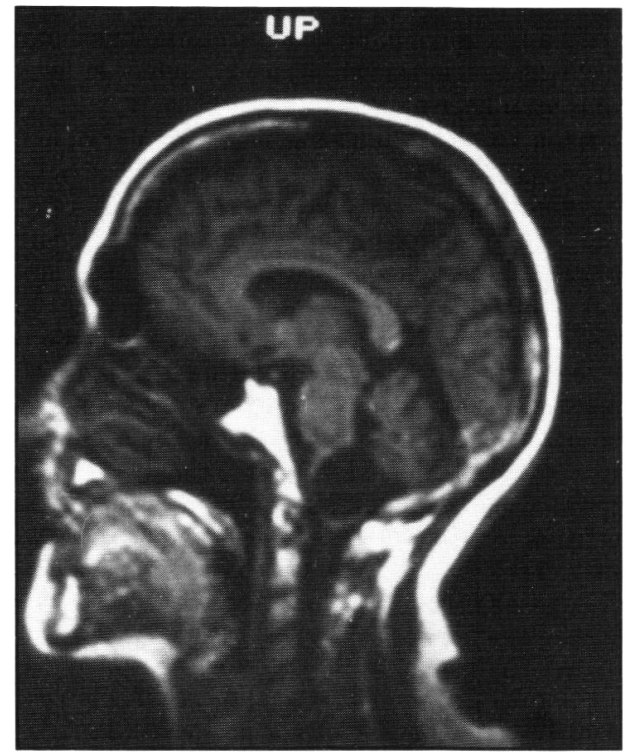

A

Figure IA - Pre-operative MRI. Lateral and horizontal views of the cyst in the medulla oblongata.

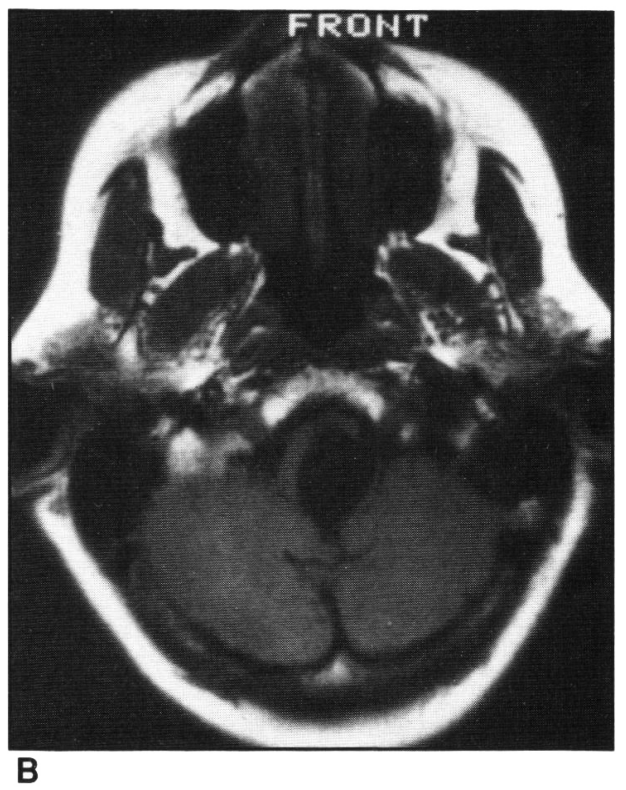

Figure $1 B$ - Pre-operative MRI. Lateral and horizontal view's of the cyst in the ntedulla oblongata 


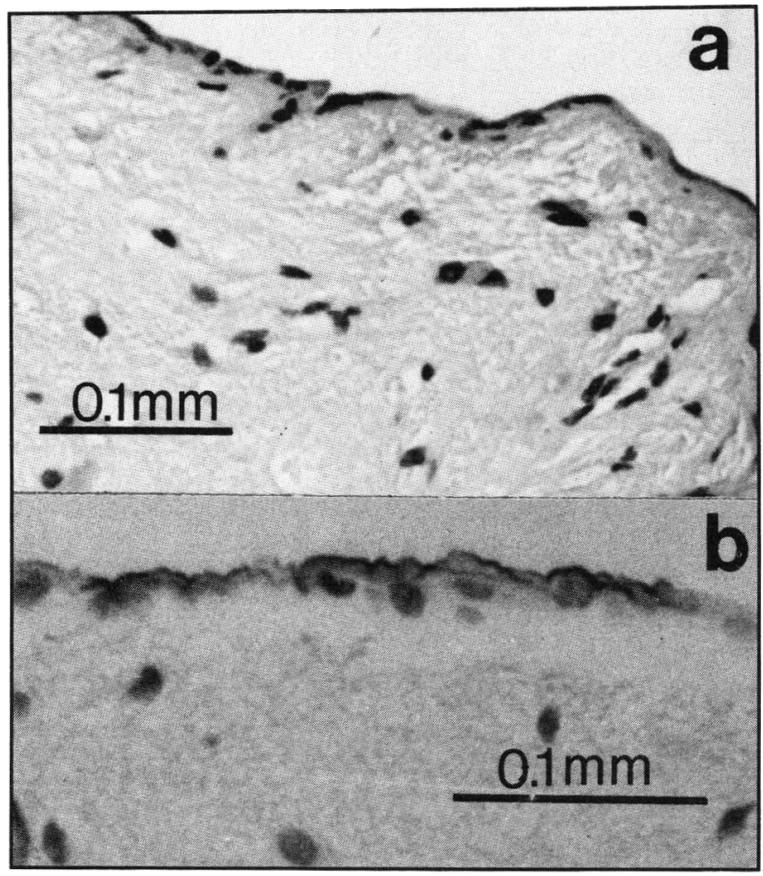

Figure $2-A$ ) Single layer of flattened epithelial cells lining the cyst. H\&E Magn 200X. B) Surface reaction for Ulex Europeus lectin. Magn 250X.

On electronmicroscopic examination, the cyst was lined by a single layer of flattened elongated cells. They overlapped each other and showed numerous short processes with frequent desmosomes (Figure 3a). The surface was studded with short microvilli coated by a layer of glycocalyx (Figure $3 \mathrm{~b}$ ). The cytoplasm was relatively electron-dense with criss-crossing, loosely arranged intermediate filaments and occasional bundles of tonofilaments. All cells showed well developed Golgi apparatus, short stacks of rough endoplasmic reticulum, occasional microtubules, a moderate number of mitochondria and large collections of glycogen particles. Neither cilia, secretory granules nor mucin were present. The epithelium was separated from the brain parenchyma by a prominent basal lamina and a layer of loose collagenous connective tissue with occasional fibroblasts and macrophages. The underlying brain showed tightly-packed collections of dystrophic neuritic processes. The remainder of the parenchyma revealed no abnormalities. The opposite, ependymal side of the specimen showed typical ependymal cells with numerous villi and cilia as well as fre- quent lateral zonulae adherentes and gap junctions. The "inner" intraparenchymal portions of the ependymal cells formed long processes filled with intermediate filaments indistinguishable from the processes of the adjacent astrocytic cells.

\section{Discussion}

Intracranial cysts represent a heterogenous group of lesions histogenetically related to the endoderm, ectoderm and neuroepithelium of the choroid plexus and ependyma. The origin of epithelium from the endodermal lining of primitive gut is favoured for Rathke cleft cysts, 4,5 enteric cysts $4,16.19 .24 .25$ and colloid cysts of the IIIrd ventricle.33,34 Additional, potential sources of intracranial "neuroepithelial" cysts include choroid plexus, ependyma and pharaphysis $2,10,12,20-23,31$ and a metaplastic "epithelial transformation" of arachnoidal cells of the leptomeninges. 18 However, determination of the origin of the lining cells on the basis of their morphological appearance alone is often difficult, since the characteristic features of ectodermal and endodermal differentiation, such as keratinization, "surface coating" or mucin production, can be present only focally. 16,24.25.34 Absence of the basal lamina has been considered an important criterion in differentiating "ependymal cysts" from other parenchymal cysts of neuroaxis. 2,6,12,20-22,25,28

The ultrastructural appearance of the lining epithelium in our material is indistinguishable from that in other cases, that have been reported variously as an intraspinal and intracerebral epithelial cysts, ${ }^{24,25}$ choroidal epithelial cysts, ${ }^{20}$ prepontine epithelial cyst, ${ }^{27}$ colloid cyst of the IIIrd ventricle ${ }^{33,34}$ and enteric cyst. ${ }^{15,16}$ These striking morphological similarities suggest that all these lesions likely represent the same histogenetic entity, differing only in the location.

Only very few immunohistochemical studies have been carried out on the parenchymal cysts of the neuroaxis. 12,15,28,31 Reported absence of GFAP ${ }^{27}$ added little to the understanding of the histogenesis of the epithelium, since not only endoderm but also epithelium of the normal choroid plexus and ependyma can be negative for glial filaments. ${ }^{32,35}$ Recently, Walls et al. ${ }^{15}$ demonstrated positive reactions for EMA, 36 milk-fat globule antigen and cytokeratins in the cells lining multiple intracranial "enteric cysts", enforcing the hypothesis of the endodermal origin of these lesions. Others show also positive reactions for S100 and carcinoembryonic antigen. ${ }^{31}$ Co-expression of keratins, cytokeratins and EMA in the epithelium in our case is very similar to the findings of Walls ${ }^{15}$ and to those reported for the colloid cysts of the IIIrd ventricle 31,34 as well as for simple epithelia of gastrointestinal tract. ${ }^{37}$ Although the normal choroid plexus also

Table 1: Distribution of Immunohistochemical Reactions in the Epithelium of the Cyst and Ependyma of the IVth Ventricle

\begin{tabular}{|c|c|c|c|c|c|c|c|c|c|c|c|c|c|}
\hline Antigen & $\mathbf{U E}$ & $\mathbf{R C}$ & EMA & KER & CK & GFAP & VIMI & $S 100$ & $\begin{array}{l}\text { PRE } \\
\text { ALR }\end{array}$ & NSE & $\begin{array}{c}\text { LEU } \\
\text { M1 }\end{array}$ & $\begin{array}{c}\text { LEU } \\
7 \\
\end{array}$ & $\begin{array}{r}\mathrm{NF} \\
70 \\
\end{array}$ \\
\hline Lining of Cyst & +++ & + & $\stackrel{++}{S}$ & + & + & - & - & - & - & - & - & - & - \\
\hline $\begin{array}{l}\text { Epcndyma of the } \\
\text { IVth Ventricle }\end{array}$ & - & $+t$ & $\begin{array}{c}+++ \\
S\end{array}$ & - & - & +++ & - & $\stackrel{+}{\mathrm{NC}}$ & - & $\begin{array}{l}- \\
-\end{array}$ & $\begin{array}{l}- \\
-\end{array}$ & $\begin{array}{l}- \\
-\end{array}$ & - \\
\hline
\end{tabular}

UE - Ulex Europeus, RC - Ricinus Communis,

EMA - Epithelial membrane antigen,

KER - Keratin, CK - Cytokeratin, GFAP - Glial fibrillary acidic protein,
VIM - Vimentin, NSE - Neuron specific enolase, NF70 - Neurofilament protein,

$\mathrm{S}$ - surface, $\mathrm{N}$ - nucleus, $\mathrm{C}$ - cyloplasm PRE-ALB — Prealbumin 


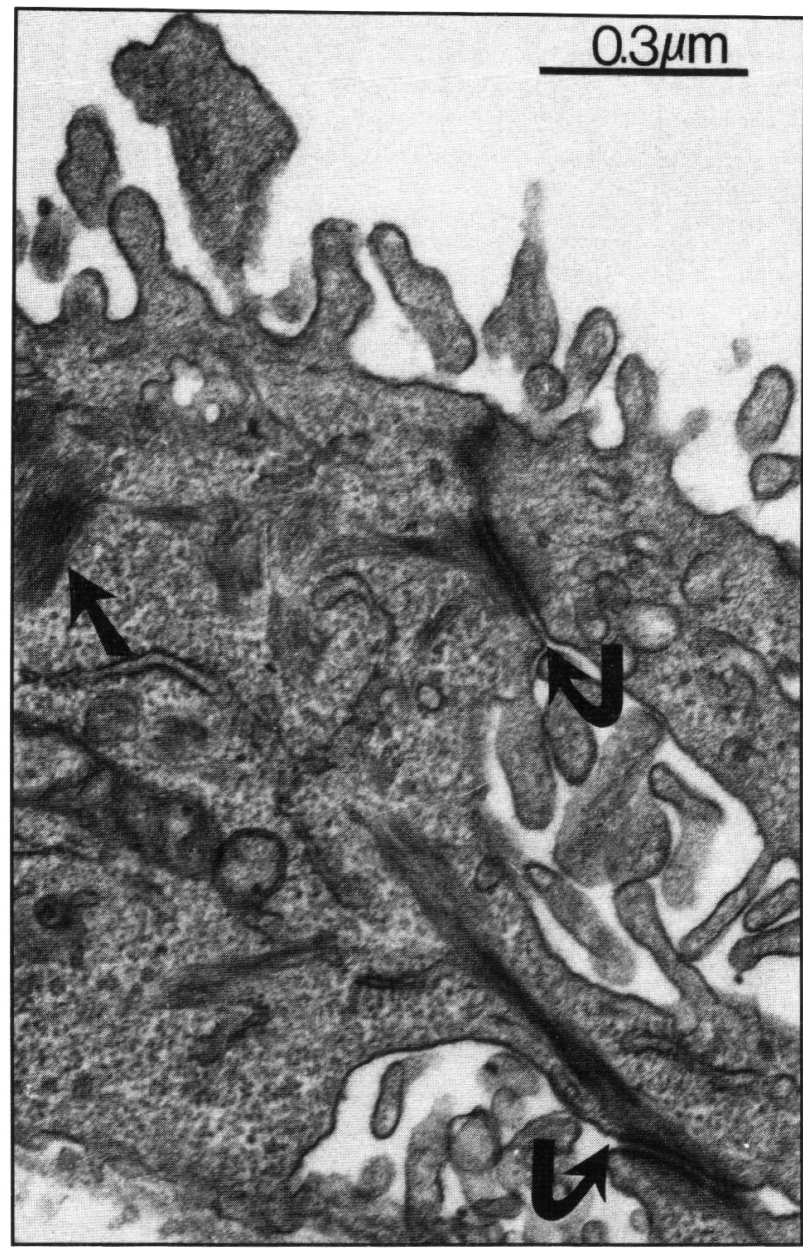

Figure 3-A) Electronmicrograph of the epithelium of the cyst Arrows point to desmosomes (curved) and tonofilaments (straight). Magn $250 X$

contains keratins 8,18 and 1935,38,39 it shows distinctive immunoreactivity for prealbumin 21.31 absent from the epithelium in our case. We were not able to confirm the presence of NF protein in the normal control choroid plexus or to localize it in the examined cyst. Negative reaction for prealbumin and ultrastructural demonstration of glycocalix and tonofilaments, indicate that the origin of this cyst from the choroid plexus is most unlikely.

Lectin histochemistry identifies specific patterns of glycosylatin of cell membranes helpful in characterization of cell types. ${ }^{40}$ Both UE and $\mathrm{RC}$ lectins have been localized in the normal and pathological epithelia of gastrointestinal 40 and respiratory tract, 40,41 and in epidermis. ${ }^{40}$ Although normal choroid plexus epithelium and occasional ependymal cells can be positive for $\mathrm{RC}$ lectin (personal observation), both of these cell types are uniformly negative for UE. ${ }^{34}$ On the other hand, strong UE immunoreactions were demonstrated on the epithelia of the colloid cysts and endodermal tissues but not on normal choroid plexus or ependyma. ${ }^{34}$ Side-by-side presence of ependyma of the IVth ventricle and lining of the cyst in our specimen, offered an internal control of the morphological and immunohistochemical studies and pointed to clearcut differences between these two epithelia. The cells of the cyst were negative for GFAP and S-100, and strongly immunoreactive for keratins, EMA and UE.

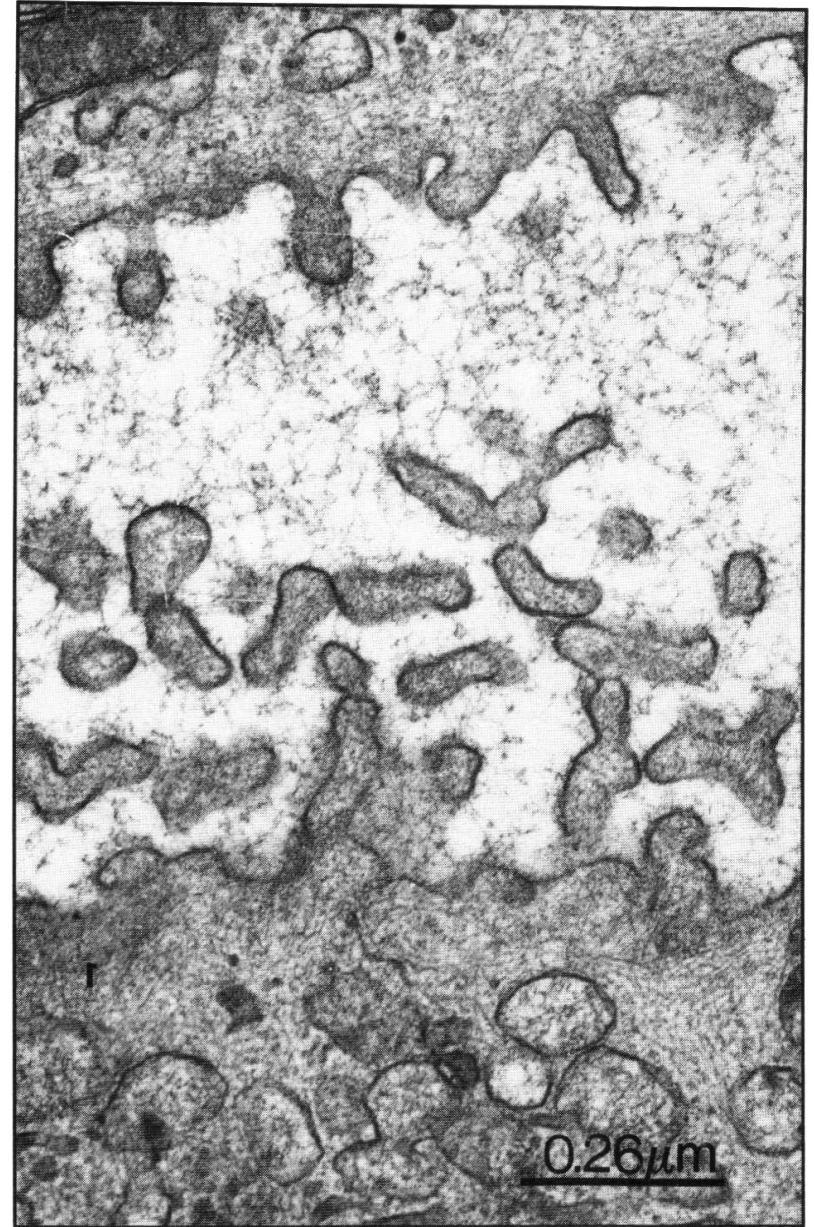

Figure $3-B$ ) Glycocalyx coating on the surface of epithelial cells. Magn 49,000X

The overall immunohistochemical properties and the ultrastructural features of this cyst were similar to colloid cyst ${ }^{33,34}$ as well as Rathke cleft cyst ${ }^{31}$ and enteric cysts ${ }^{16.24,31}$ of the spinal cord and cranium. ${ }^{15}$ Although anti-NF, VIM, Ml and Leu 7 antibodies have a recognized role in neurooncology, 42 they have not contributed to the differential diagnosis in our case.

It has been reported that the lining epithelia of the enteric cysts may correspond to specific regions of alimentary or respiratory tract. ${ }^{1}$ The lining can be composed of a simple type of epithelium 25.29 as well as squamous, goblet 16 or ciliated cells ${ }^{16,24,25}$ and show glycocalyx coating. 15,16,24 Epithelium in our case displayed only one line of epithelial differentiation to squamous cells, some coated by glycocalyx. Regardless of the nature of the epithelium, the delayed onset of symptoms (at the median age of 46), in patients with intraparenchymal cysts of neuroaxis indicates their slowly progressive expansion. 2.3 Pinocytic activity of the lining cells and active cellular transport of fluids have been proposed as one mechanism of their enlargement. ${ }^{25}$ Alternative explanations include an osmotic pressure gradient exerted by high protein content ${ }^{3}$ or a secretory activity of the lining epithelium. ${ }^{2.22}$

The clinical diagnosis of intracranial cysts has improved markedly since the advent of CT-scanning. However, some cysts have attenuation values similar to those of brain tissue, 28 
while others show density similar to cerebrospinal fluid. 10,15,20,21,27 CT-scan density in our case was identical to that of brain parenchyma, a feature which rendered it undetectable until MRI examination. A similar experience with negative CT-scan findings and positive MRI has recently been reported in other cases of intramedullary cyst. ${ }^{43}$ The treatment of an epithelial cyst of the medulla is compromised by its location in a vitally important region. Marked improvement of the symptoms after drainage of the cyst into the IVth ventricle in our patient is similar to the results that have been obtained by drainage or shunting of the cysts to the subarachnoid space.12 However, as in other cysts of the $\mathrm{CNS}^{44}$ the residual epithelium remaining in the brain has proliferative and secretory potential, and the patient is being closely followed up for signs of regrowth or re-expansion of the lesion.

\section{ACKNOWLEDGEMENTS}

The authors would like to express their appreciation to Ms. B. Kosabek-Williams and Mr. A. Gregor in the Laboratory of Neuropathology, and all the technologists in the Laboratory of Electronmicroscopy for their expert technical assistance. We would also like to thank Ms. E. Lortie and Ms. E. Lach for the typing and word processing of this manuscript.

\section{REFERENCES}

1. Friede RL. Developmental neuropathology, Springer-Verlag, New York-Wien, 1975; 196-202 and 266-271.

2. Friede RL, Yasargil M. Supratentorial epithelial (ependymal) cysts: Review, case reports, and fine structure. J Neurol Neurosurg Psych 1977; 40: 127-137.

3. Jakubiak P, Dunsmore RH, Beckett RS. Supratentorial brain cysts. J Neurosurg 1968; 28: 129-136.

4. Leech RW, Olafson RA. Epithelial cysts of neuroaxis. Arch Pathol Lab Med 1977; 101: 196-202.

5. Rubinstein LJ. Tumors of the central nervous system. Atlas of tumor pathology. Second series. Fasc 6, Armed Forces Inst. of Path. Washington, DC; 1972; 285-292.

6. Bouch DC. Mitchell I, Maloney AFJ. Ependymal lined paraventricular cerebral cysts: A report of three cases. J Neurol Neurosurg Psych 1973; 36: 611-617.

7. Rilliet B, Berney J. Benign ependymal cyst of the pons. Childs Brain 1981; 8: 1-8.

8. Sharma BS, Banerjee AK, Khosla VK, et al. Congenital intramedullary spinal ependymal cyst. Surg Neurol 1987; 27: 476-480.

9. Ho KL, Chasen JL. A glioependymal cyst of the cerebello-pontine angle. Immunohistochemical and ultrastructural studies. Acta Neuropath (Berl) 1987; 74: 382-388.

10. Andrews BT, Halks-Miller M, Berger MS, et al. Neuroepithelial cyst of the posterior fossa: Pathogenesis and report of two cases. Neurosurg 1984; 15: 91-95.

11. Hasagawa $\mathrm{H}$, Ushio $\mathrm{Y}, \mathrm{Oku} \mathrm{Y}$, et al. Neuroepithelial cyst of the cerebellar vermis. Surg Neurol 1976; 6: 181-184.

12. Pokrupa R, Montpetit V, Richard M. Fine structure and postulated origin of intracerebral neuroepithelial cyst. Neuropath Exp Neurol 1983; 42: 356(A).

13. Afshar F, Scholtz CL. Enterogenous cyst of the fourth ventricle. J Neurosurg 1981; 54: 836-838.

14. Giombini $S$, Lodrini $S$, Migiliavacca $F$. Intracranial enterogenous cyst. Surg Neurol 1981; 6: 181, 16:271-273.

15. Walls TJ, Purohit DP, Aji WS, et al. Multiple intracranial enterogenous cysts. J Neurol Neurosurg Psych 1986; 49: 438-44l.

16. Matsushima T, Fukui M, Egami H. Epithelial cells in a so-called intraspinal neuroenteric cyst: A light and electromicroscopic study. Surg Neurol 1985; 24: 656-660.

17. Yamashita J, Maloney AFJ, Harris P. Intradural spinal bronchogenic cyst. Case report. J Neurosurg 1973; 39: 240-1245.
18. Schelper RL, Kagan-Hallett KS, Huntington HW. Brainstem subarachnoid respiratory epithelial cysts. Report of two cases and review of literature. Hum Pathol 1986; 17: 417-422.

19. Dorsay JF, Tabrisky J. Intraspinal and mediastial foregut cyst compressing spinal cord: Report of a case. J Neurosurg 1966; 24: $562-567$.

20. Inoue T, Kuromatsu C, Iwata $\mathrm{Y}$, et al. Symptomatic choroidal epithelial cyst in the fourth ventricle. Surg Neurol 1985; 24: 57-62.

21. Inoue $T$, Masushima $T$, Fukuyi $M$, et al. Choroidal epithelial cysts of the cerebral hemisphere. An immunohistochemical study. Surg Neurol 1987; 28: 119-122.

22. Koto A, Horoupian DS, Shulman K. Choroidal epithelial cyst. Case report. J Neurosurg 1977; 47: 955-960.

23. Netsky MG, Shuangshoti GS. The choroid plexus in Health and Disease. Wright and Sons, Bristol 1975; 199-248.

24. Hirano A, Ghatak NR, Wisoff HS, et al. An epithelial cyst of the spinal cord. An electron microscopy study. Acta Neuropath (Berl) 1971; 214-223

25. Ghatak NR, Hirano A, Kassoff SS, et al. Fine structure of an intracerebral epithelial cyst. J Neurosurg 1974; 41: 75-82.

26. MacGregor BJL, Gawler J, South JR. Intracranial epithelial cysts. Report of two cases. J Neurosurg 1976; 44: 109-115.

27. Hirai O, Kawamura J, Fukumitsu T. Prepontine epithelium-lined cyst. Neurosurg 1981; 55: 312-317.

28. Gherardi R, Lacombe MJ, Poirier J, et al. Asymptomatic encephalic intraparenchymatous neuroepithelial cysts. Acta Neuropath (Berl) 1984; 63: 264-268.

29. Mortara RH, Marksbery WR, Brooks WH. Pontine cyst presenting as trigeminal pain. Case report. J Neurosurg 1974; 41:636-639.

30. Scott M, Silverstein A. Intrapontine cyst verified by surgical drainage into the fourth ventricle. J Neurosurg 1960; 17: 520-. 528.

31. Inoue $T$, Matsushima $T$, Fukui $M$, et al. Immunohistochemical study of Intracranial Cysts. Neurosurg 1988; 23: 576-581.

32. Izukawa D, Lach B. Immunocytochemical analysis of intermediate filaments in human ependymal tumors. Can J Neurol Sci 1988; 15: 114-118.

33. Hirano A, Ghatak NR. The fine structure of colloid cysts of the third ventricle. J Neuropathol Exper Neurol 1974; 33: 333-341.

34. Lach B, Scheithauer, Wick MR. Histogenesis of the colloid cyst. Ultrastructural and immunohistochemical studies. Presented at the IVth Congress of Neuropathology, Stockholm, Sept. 1986.

35. Miettinen M, Clark R, Virtanen I. Intermediate filament proteins in choroid plexus and ependyma and their tumors. Am J Path 1986; 123: $231-240$.

36. Sloan JP, Ormerod MG. Distribution of epithelial membrane antigen in normal and neoplastic tissues and its value in diagnostic tumor pathology. Cancer 1981; 47: 1786-1795.

37. Cooper D, Schermer A, Sun TT. Classification of human epithelia and their neoplasms using monoclonal antibodies to keratins: Strategies, applications and limitations. Lab Invest 1985; 52: 143-256.

38. Coffin ChM, Wick MR, Braun JT, et al. Choroid plexus neoplasms, clinicopathologic and immunohistochemical studies. Am J Surg Pathol 1986; 10: 394-404.

39. Kasper M, Karsten U, Stosiek P. Detection of cytokeratin(s) in epithelium of human plexus choroideus by monoclonal antibodies. Acta Histochem 1986; 8: 101-103.

40. Damianov I. Biology of disease. Lectin cytochemistry and histochemistry. Lab Invest 1987; 57: 5-20.

41. Geleff S, Bock P, Stockinger L. Lectin-binding affinities of the epithelium in the respiratory tract. A light microscopical study of ciliated epithelium in rat, guinea pig and hamster. Acta Histochem 1986; 78: 83-95.

42. Perentes E, Rubinstein LJ. Recent applications of immuno-peroxidase histochemistry in human neuro-oncology. Arch Path Lab Med III 1987; 796-812.

43. Pinel JF, Larmande P, Guegan Y, Iba-Zizen MT. Down-beat nystagnus: Case report with magnetic resonance imaging and surgical treatment. Neurosurgery 1987; 21: 736-739.

44. McKissock W. The surgical treatment of colloid cyst of the third ventricle. A report based upon twenty-one personal cases. Brain 1951: $74: 1-9$ 